\title{
Cardioplegia and vascular injury
}

\section{Dissociation of the effects of ischemia from those of the cardioplegic solution}

\begin{abstract}
Although cardioplegic solutions successfully protect myocardial contractile cells against ischemic injury, their effect on the vasculature remains controversial. To address this we used a vascular bed preparation (isolated rat mesentery) that permits the study of vascular function without the coincident changes in contractile status that affect vascular tone (and hence the assessment of vascular function in isolated hearts). Smooth muscle cell contraction was assessed by measurement of the vasoconstrictor response to phenylephrine, and relaxation was assessed by measurement of the vasodilator responses to sodium nitroprusside and the endothelium-dependent relaxant adenosine triphosphate. After characterization of basal vascular function, mesenteries were subjected to normothermic ischemia for $\mathbf{6 0}, \mathbf{9 0}$, 120,150 , and 180 minutes $(n=12$ for each time period; 6 preparations were subjected to ischemia alone and 6 to ischemia preceded by a 3-minute infusion of the St. Thomas' Hospital cardioplegic solution). The tissue was then reperfused for $\mathbf{2 0}$ minutes and vascular function reassessed. Ischemia alone caused progressive time-dependent deterioration in vasoconstrictor responses $(99 \% \pm 13 \%$, $90 \% \pm 10 \%, 63 \% \pm 6 \%, 51 \% \pm 10 \%$, and $27 \% \pm 4 \%$ ), endothelium-independent vasodilation $(93 \% \pm 3 \%, 86 \% \pm 2 \%, 78 \% \pm 5 \%, 61 \% \pm 5 \%$, and $38 \% \pm 9 \%)$, and endothelium-dependent vasodilation $(93 \% \pm 3 \%, 96 \% \pm 2 \%, 94 \% \pm 2 \%, 87 \% \pm 7 \%$, and $62 \% \pm 11 \%)$. There were similar time-dependent deteriorations in mesenteries subjected to ischemia coupled with cardioplegic solution that were not significantly different from any of the ischemia-alone groups when matched for ischemic times. Thus, for example, after 180 minutes of ischemia alone, the vasoconstrictor response was $18 \% \pm 3 \%$, endothelium-independent vasodilation was $44 \% \pm 7 \%$, and endothelium-dependent vasodilation was $40 \% \pm 9 \%$. The results demonstrate that under the conditions of this experiment, the St. Thomas' Hospital cardioplegic solution neither protects nor injures the vasculature during an episode of ischemia and reperfusion. However, in studies with 150 minutes of normothermic ischemia, multiple infusions of cardioplegic solution (given every $\mathbf{3 0}$ minutes during ischemia) resulted in protection of smooth muscle and endothelial function. Thus, after multiple infusions, vasoconstriction to phenylephrine was $74 \% \pm 4 \%$, vasodilation to nitroprusside was $81 \% \pm 6 \%$, and vasodilation to adenosine triphosphate was $89 \% \pm 5 \%$. In conclusion, when the St. Thomas' Hospital cardioplegic solution is used as a single infusion and coupled with ischemia, the solution fails to protect smooth muscle and endothelial function against ischemic injury, but some protection is obtained when the solution is infused intermittently throughout the ischemic period. (J THORAC Cardiovasc Surg 1994;108:279-90)
\end{abstract}

Clyde Saldanha, BSc, MB BS, FRCS (Ed), and David J. Hearse, PhD, DSc, London, United Kingdom

From Cardiovascular Research, The Rayne Institute, St. Thomas' Hospital, London, United Kingdom.

Supported by The Special Trustees for St. Thomas' Hospital.

Received for publication Aug. 5, 1993.

Accepted for publication Feb. 4, 1994
Address for reprints: Clyde Saldanha, FRCS (Ed), Department of Cardiothoracic Surgery, St. Bartholomew's Hospital, London EC1A 7BE, United Kingdom.

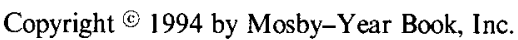

$0022-5223 / 94 \$ 3.00+0 \quad \mathbf{1 2} / \mathbf{1} / \mathbf{5 5 5 9 9}$ 
Cardioplegia is the most widely used technique for myocardial preservation during heart operations. This can be attributed to extensive experimental and clinical data that demonstrate that cardioplegia protects the cardiac myocyte against a loss of contractile capability arising as a consequence of ischemic injury. ${ }^{1,2}$ The effects of cardioplegic solutions and their chemical constituents on other cellular components of the heart (such as the vasculature) have been less clearly characterized. Microvascular preservation is an important aspect of overall myocardial protection and there is increasing evidence that damage to the endothelium may contribute significantly to the determination of the overall ability of the heart to recover from an episode of ischemia and reperfusion. ${ }^{3,4}$

In the heart, endothelial cells have an exceptionally high surface area $\left(1000 \mathrm{~cm}^{2} / \mathrm{gm}\right)^{4}$ and also represent approximately $3 \%$ of the total myocardial volume. ${ }^{5}$ These cells form a continuous vascular lining, providing a selective barrier that effectively separates intravascular and extravascular spaces. It is now established that the vascular endothelium performs several important functions including vasoregulation, hemostasis, and modulation of local inflammatory responses. ${ }^{3,6-9}$ One of the most important factors produced by the endothelium is endotheliumderived relaxing factor (EDRF) ${ }^{10}$ which is a short-lived intermediate and has been identified as nitric oxide. ${ }^{11}$ Damage to the endothelium with loss of EDRF has been implicated as a major factor in the pathophysiologic basis of injury induced by ischemia and reperfusion. ${ }^{12,13}$ There is also evidence to suggest that regenerated endothelial cells may not fully recover their ability to release EDRF. ${ }^{14}$

Several studies have reported morphologic and functional evidence of endothelial damage associated with the use of cardioplegic solutions. ${ }^{15-20}$ There has been a tendency to attribute the damage to a direct toxic effect of the cardioplegic solution. ${ }^{15,19,20}$ However, cardioplegia is conventionally used in combination with other potentially deleterious conditions such as elective ischemia and reperfusion, both of which are also known to produce endothelial damage. ${ }^{12,21,22}$ To date, the dissociation of damage caused by ischemia or reperfusion, or both, from damage attributable to the solution per se has not been clearly established. Resolution of this issue is desirable, inasmuch as not only might the information influence the future composition and mode of administration of cardioplegic solutions, but it should also contribute to furthering our understanding of microvascular function and injury. Thus if damage is caused predominantly by a toxic effect of the solution, then toxic components could be identified and possibly eliminated. If, however, the damage is mainly a result of the failure of the cardioplegic solution to protect the vasculature against ischemia-reperfusion injury, then additional protective agents may be added and targeted specifically at the vasculature. Another possibility (by analogy with protection of the myocyte) is that the beneficial or detrimental effects of a solution might be dependent on the frequency of its administration. ${ }^{23-25}$

Relative to measuring myocyte injury, two difficulties inherent in the study of microvascular injury in the heart are (1) the difficulty of identifying and quantifying acceptable indices of vascular function and injury and (2) the confounding effects of coincident injury to the myocyte (for example, contracture) that can influence coronary perfusion and hence the ability to identify vascular changes that arise solely as a consequence of injury to vascular tissue. For these reasons we have established a vascular bed preparation (the isolated perfused mesentery) in which it is possible to infuse cardioplegic solutions and induce controlled ischemia while being able to measure temporal changes in smooth muscle reactivity mediated by both endothelium-dependent and endotheliumindependent mechanisms.

The first objective of the present study was to use this preparation to compare the consequences on endothelial and smooth muscle function of ischemia alone versus ischemia combined with the St. Thomas' Hospital cardioplegic solution. The study was designed to assess any differences over a spectrum of ischemic periods that equate with those used during heart operation. Experiments were done under normothermic conditions because previous studies have demonstrated that hypothermia per se has a detrimental effect on endothelial cells. ${ }^{26,}{ }^{27}$ In the second part of the study, the effects of single versus multiple infusions of cardioplegic solution on endothelial and smooth muscle function after an extended period of ischemia were compared.

\section{Material and methods}

Animals. All experiments were done with male Wistar rats ( 275 to $325 \mathrm{gm}$ body weight) that had been maintained on a standard laboratory diet. The animals received humane care in compliance with the "Principles of Laboratory Care" formulated by the National Society for Medical Research and the "Guide for the Care and Use of Laboratory Animals" prepared by the National Academy of Sciences and published by the National Institutes of Health (NIH Publication No. 86-23, revised 1985). The investigation was performed in accordance with the Home Office "Guidance on the Operation of Animals (Scientific Procedures) Act," 1986.

Mesenteric dissection technique. The mesenteric preparations used for these experiments were based on the method of McGregor. ${ }^{28}$ Rats were anesthetized by intraperitoneal injection ( $6 \mathrm{mg} / 100 \mathrm{gm}$ body weight) of pentobarbital sodium. After induction of anesthesia the left femoral vein was exposed and heparin ( $100 \mathrm{IU} / 100 \mathrm{gm}$ body weight) injected. The abdomen was opened and the aorta and superior mesenteric artery were 


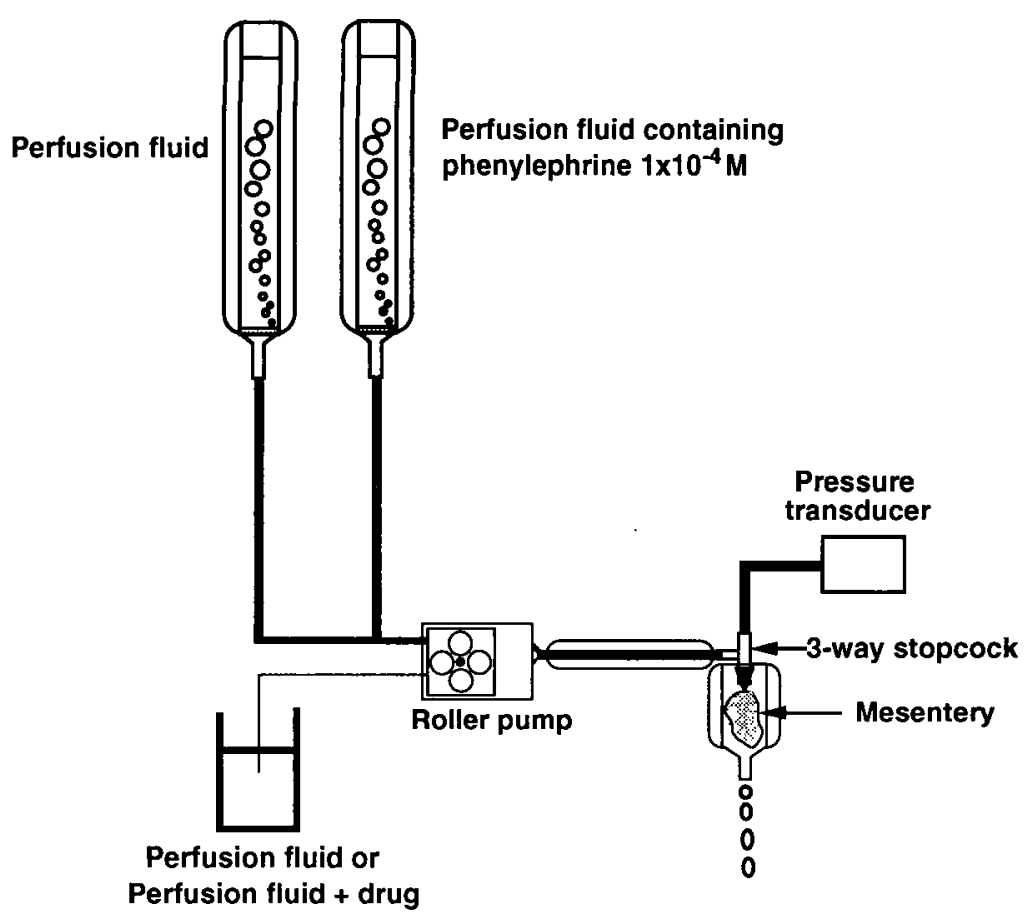

Fig. 1. Experimental preparation for perfusing and assessing vascular function in isolated rat mesentery.

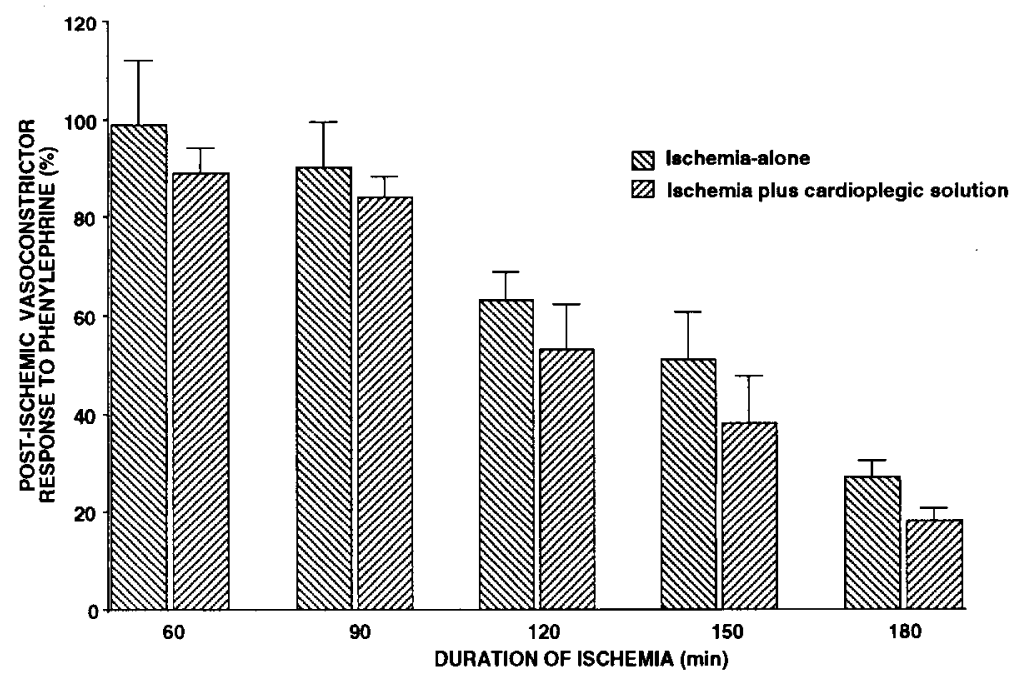

Fig. 2. Postischemic smooth muscle contractile function in response to phenylephrine $\left(1 \times 10^{-4} \mathrm{~mol} / \mathrm{L}\right)$ expressed as percentage of preischemic function after 60 to 180 minutes of ischemia alone or of ischemia plus cardioplegic solution.

identified and cleared of superficial tissue by gentle strokes with a moist cotton swab. The proximal portion of the superior mesenteric artery was further exposed by sharp dissection and a 3-0 braided silk thread was passed behind the artery. The ileocecal artery was then identified and tied off distally with 3-0 silk thread. The mesentery was then dissected from the cecum, small intestine, and large intestine, with the cuts made as close to the intestine as possible. Once this was completed the mesentery was dissected free from the spleen and the stomach. A syringe $(2 \mathrm{ml})$ was then connected to the Luer-Lok mount (Becton Dickinson \& Co., Becton Dickinson Division, Rutherford, N.J.) of a $3 \mathrm{~F}$ intravenous cannula that had been shortened 


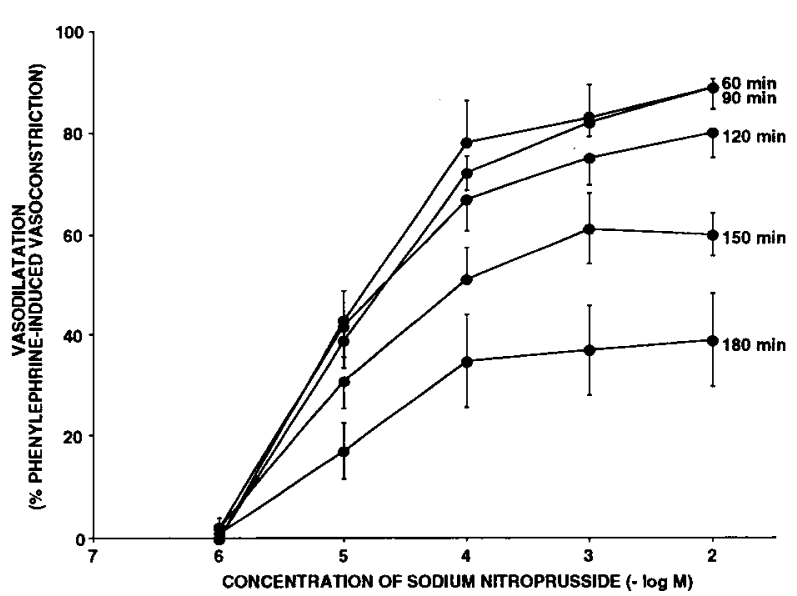

Fig. 3. Vasodilation to sodium nitroprusside expressed as percent of phenylephrine-induced vasoconstriction after 60,90 , 120,150 , or 180 minutes of ischemia alone.

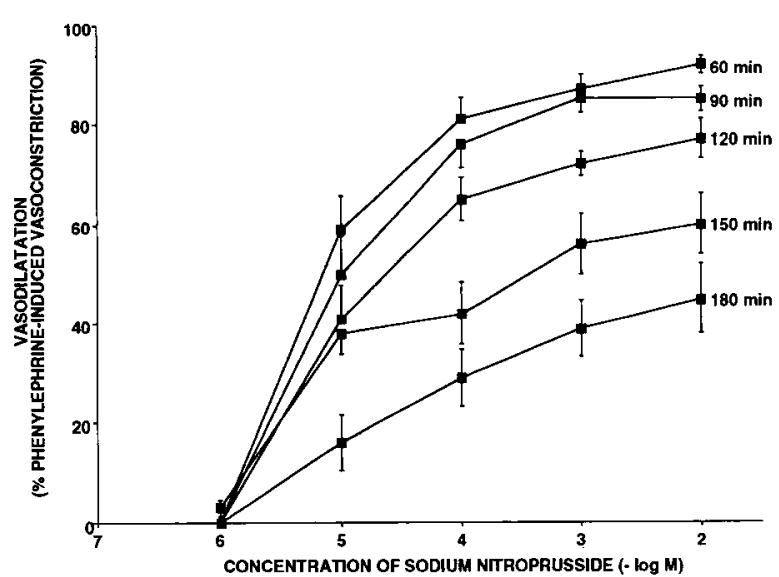

Fig. 4. Vasodilation to sodium nitroprusside expressed as percent of phenylephrine-induced vasoconstriction after 60, 90 , 120,150 , or 180 minutes of ischemia plus cardioplegic solution.

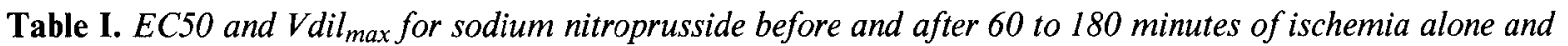
ischemia plus cardioplegic solution

\begin{tabular}{|c|c|c|c|c|}
\hline $\begin{array}{c}\text { Experimental } \\
\text { condition }\end{array}$ & $\begin{array}{c}\text { EC50 } \\
\text { before ischemia } \\
(-\log \mathrm{mol} / \mathrm{L})\end{array}$ & $\begin{array}{c}\text { EC50 } \\
\text { after ischemia } \\
(-\log \mathrm{mol} / \mathrm{L})\end{array}$ & $\begin{array}{c}V_{\text {dil }} \\
\text { before ischemia } \\
(\%)\end{array}$ & $\begin{array}{c}\text { Vdil } l_{\max } \\
\text { after ischemia } \\
(\%)\end{array}$ \\
\hline $60 \min I$ & $5.0 \pm 0.1$ & $4.8 \pm 0.1$ & $91 \pm 2$ & $93 \pm 3$ \\
\hline $60 \min I+C$ & $5.3 \pm 0.1$ & $5.1 \pm 0.1$ & $93 \pm 2$ & $88 \pm 2^{*}$ \\
\hline $90 \min I$ & $5.3 \pm 0.1$ & $4.8 \pm 0.1^{*}$ & $94 \pm 2$ & $86 \pm 2^{*}$ \\
\hline $90 \min \mathrm{I}+\mathrm{C}$ & $5.0 \pm 0.1$ & $4.9 \pm 0.1$ & $91 \pm 2$ & $85 \pm 2^{*}$ \\
\hline $120 \min I$ & $5.0 \pm 0.1$ & $4.9 \pm 0.1$ & $90 \pm 2$ & $78 \pm 5^{*}$ \\
\hline $120 \min \mathrm{I}+\mathrm{C}$ & $5.1 \pm 0.1$ & $4.9 \pm 0.1$ & $95 \pm 1$ & $74 \pm 3^{*}$ \\
\hline $150 \mathrm{~min} I$ & $5.1 \pm 0.1$ & $4.9 \pm 0.1$ & $92 \pm 2$ & $61 \pm 5^{*}$ \\
\hline $150 \min I+C$ & $4.9 \pm 0.1$ & $4.6 \pm 0.2$ & $92 \pm 2$ & $62 \pm 6^{*}$ \\
\hline $180 \min I$ & $5.3 \pm 0.1$ & $4.8 \pm 0.1^{*}$ & $90 \pm 2$ & $38 \pm 9^{*}$ \\
\hline $180 \min \mathrm{I}+\mathrm{C}$ & $5.1 \pm 0.1$ & $4.4 \pm 0.3$ & $92 \pm 1$ & $44 \pm 7^{*}$ \\
\hline
\end{tabular}

$I$, Ischemia alone; $I+C$, ischemia plus cardioplegic solution.

${ }^{*} p<0.05$ compared with preischemic value.

to $5 \mathrm{~cm}$. The cannula was flushed and the syringe primed with perfusion solution (see following section). The aorta was clamped 0.5 to $1 \mathrm{~cm}$ proximal to the superior mesenteric artery with mosquito forceps. With the use of fine-pointed scissors an incision was made in the aorta directly opposite the superior mesenteric artery and the intravenous cannula inserted into the superior mesenteric artery and advanced as far as possible. The cannula was then secured with the 3-0 silk thread and the mesenteric bed flushed with perfusion solution from the syringe. The mesentery was removed from the animal, the syringe removed from the Luer-Lok syringe, and the Luer-Lok syringe connected to a three-way stopcock to allow continuous perfusion. The time taken from clamping the aorta to the initiation of perfusion was less than 90 seconds.

Perfusion technique. Mesenteries were perfused at a constant flow rate with the use of a peristaltic pump. The perfusion fluid was pumped through two tubings (Fig. 1). Tubing 1 (internal diameter, $2.06 \mathrm{~mm}$ ) carried either oxygenated perfusion fluid or oxygenated perfusion fluid that contained phenylephrine $\left(1 \times 10^{-4} \mathrm{~mol} / \mathrm{L}\right)$. Tubing 2 (internal diameter, $0.7 \mathrm{~mm}$ ) carried fluid from reservoirs that contained either perfusion fluid or perfusion fluid that contained specified drugs. The fluid from both tubes was mixed via a $\mathrm{Y}$ piece connector and passed through a heated glass coil $\left(37^{\circ} \mathrm{C}\right)$ before it perfused the mesentery. The final temperature of the perfusate was $37^{\circ} \mathrm{C}$ at a constant flow rate of $8.3 \mathrm{ml} / \mathrm{min}(7.5 \mathrm{ml} / \mathrm{min}$ from tubing 1 plus $0.8 \mathrm{ml} / \mathrm{min}$ from tubing 2). Initially the perfusion fluid pumped through both tubings was drug-free perfusion fluid. After the preparation had stabilized, the perfusion fluid in tubing 1 was switched to phenylephrine-containing perfusion fluid. During assessment of the vasodilatory effects of drugs, the fluid pumped through tubing 2 was changed to one of the drugcontaining fluids. Washout of drugs was accomplished by reverting to drug-free perfusion fluid. The perfusion pressure 


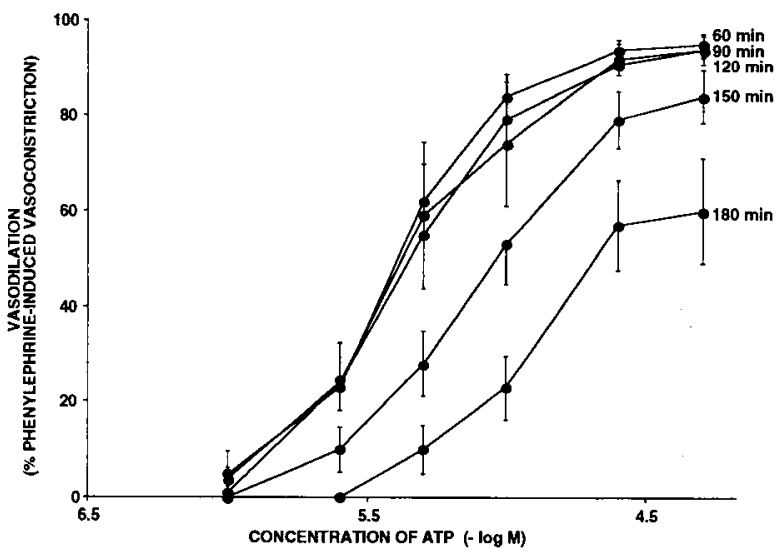

Fig. 5. Vasodilation to ATP expressed as percent of phenylephrine-induced vasoconstriction after $60,90,120,150$, or 180 minutes of ischemia alone.

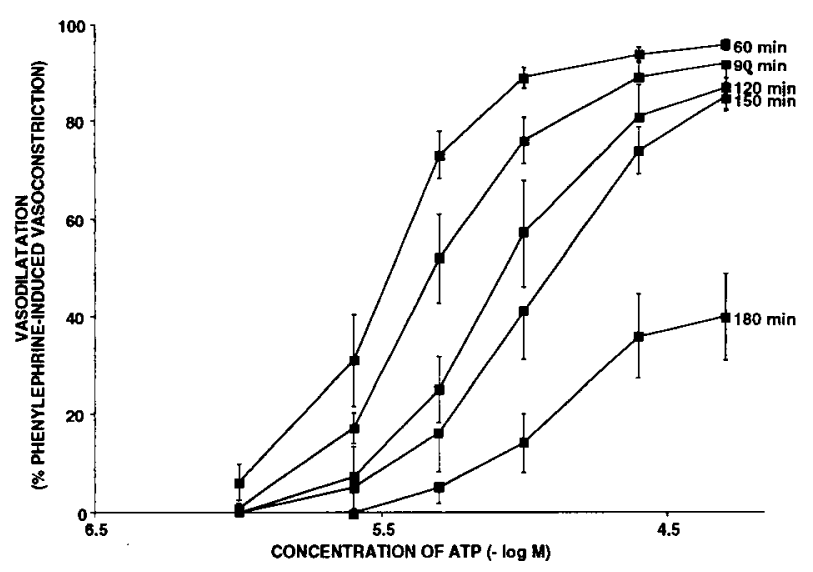

Fig. 6. Vasodilation to ATP expressed as percentage of phenylephrine-induced vasoconstriction after $60,90,120,150$, or 180 minutes of ischemia plus cardioplegic solution.

Table II. EC50 and Vdil $l_{\max }$ for ATP before and after 60 to 180 minutes of ischemia alone and ischemia plus cardioplegic solution

\begin{tabular}{|c|c|c|c|c|}
\hline $\begin{array}{c}\text { Experimental } \\
\text { condition }\end{array}$ & $\begin{array}{c}\text { EC50 } \\
\text { before ischemia } \\
(-\log \mathrm{mol} / \mathrm{L})\end{array}$ & $\begin{array}{c}\text { EC50 } \\
\text { after ischemia } \\
(-\log \text { mol/L) }\end{array}$ & $\begin{array}{c}\text { Vdil } l_{\max } \\
\text { before ischemia } \\
(\%)\end{array}$ & $\begin{array}{c}\text { Vdil }{ }_{\max } \\
\text { after ischemia } \\
(\%)\end{array}$ \\
\hline $60 \mathrm{~min} I$ & $5.5+0.1$ & $5.3+0.1$ & $99 \pm 3$ & $93 \pm 3$ \\
\hline $60 \min I+C$ & $5.6+0.1$ & $5.5+0.1$ & $95 \pm 1$ & $95 \pm 1$ \\
\hline $90 \min I$ & $5.7+0.1$ & $5.4+0.1^{*}$ & $97 \pm 1$ & $96 \pm 2$ \\
\hline $90 \min I+C$ & $5.4+0.1$ & $5.3+0.1$ & $96 \pm 1$ & $90 \pm 3$ \\
\hline $120 \mathrm{~min} I$ & $5.6 \pm 0.1$ & $5.4 \pm 0.1^{* \dagger}$ & $95 \pm 1$ & $94 \pm 2$ \\
\hline $120 \min I+C$ & $5.4 \pm 0.1$ & $5.1 \pm 0.1^{*}$ & $97 \pm 1$ & $90 \pm 3^{*}$ \\
\hline $150 \mathrm{~min} I$ & $5.5 \pm 0.1$ & $5.1 \pm 0.1^{*}$ & $94 \pm 1$ & $87 \pm 7$ \\
\hline $150 \min I+C$ & $5.6 \pm 0.1$ & $5.0 \pm 0.1^{*}$ & $96 \pm 1$ & $87 \pm 3$ \\
\hline $180 \mathrm{~min} I$ & $5.5 \pm 0.1$ & $5.0 \pm 0.1^{*}$ & $98 \pm 1$ & $62 \pm 11^{*}$ \\
\hline $180 \min I+C$ & $5.4 \pm 0.1$ & $4.9 \pm 0.1^{*}$ & $97 \pm 1$ & $40 \pm 9^{*}$ \\
\hline
\end{tabular}

$I$, Ischemia alone; $I+C$, ischemia plus cardioplegic solution.

${ }^{*} p<0.05$ compared with preischemic value.

$+p<0.05$ compared with time-matched postischemic cardioplegic value.

was continuously measured by a transducer attached to the sidearm of the three-way stopcock and recorded with a chart recorder.

Experimental time course. The mesentery was initially perfused for 10 minutes with drug-free perfusion fluid passed through both tubings 1 and 2 . After this stabilization period the fluid in tubing 1 was changed to fluid that contained phenylephrine $\left(1 \times 10^{-4} \mathrm{~mol} / \mathrm{L}\right)$. When the vasoconstrictor response to phenylephrine was stable (within 5 minutes), dose-response studies were done with the endothelium-dependent vasodilator adenosine triphosphate (ATP) and the endothelium-independent vasodilator sodium nitroprusside. This was accomplished by changing the perfusion solution in tubing 2 . For each drug, the lowest concentration was used first and infused for 2 minutes before the next highest concentration was infused. This was then perfused for 2 minutes and the process repeated until the highest dose was used. A washout period of 5 minutes was interposed between dose-responses to allow the phenylephrine-in- duced constriction to return to a stable baseline level. In all mesenteries responses were first assessed to ATP and then to nitroprusside. The concentrations of ATP used were $1 \times 10^{-6}$, $2.5 \times 10^{-6}, 5 \times 10^{-6}, 1 \times 10^{-5}, 2.5 \times 10^{-5}$, and $5 \times 10^{-5}$ $\mathrm{mol} / \mathrm{L}$; for sodium nitroprusside the concentrations were $1 \times 10^{-6}, 1 \times 10^{-5}, 1 \times 10^{-4}, 1 \times 10^{-3}$, and $1 \times 10^{-2} \mathrm{~mol} / \mathrm{L}$. After the vasodilator responses had been assessed, drug-free perfusion fluid was pumped through tubings 1 and 2 and individual protocols done as described in the experimental design section. During the ischemic period, mesenteries were immersed in $0.9 \%$ saline solution at $37^{\circ} \mathrm{C}$. At the end of the ischemic period mesenteries were reperfused for 20 minutes with drug-free perfusion fluid. Vasoconstriction was then induced with phenylephrine $\left(1 \times 10^{-4} \mathrm{~mol} / \mathrm{L}\right)$ and vasodilator responses to ATP and nitroprusside repeated as previously described.

\section{Experimental design}

Ischemia alone versus ischemia plus cardioplegic solution. 
Table III. EC50 and Vdil max for ATP before and after 150 minutes of ischemia in mesenteries receiving either single or multiple infusions of cardioplegic solution

\begin{tabular}{ccccc}
\hline $\begin{array}{c}\text { Experimental } \\
\text { condition }\end{array}$ & $\begin{array}{c}\text { EC50 } \\
\text { before ischemia } \\
(-\log \text { mol/L) }\end{array}$ & $\begin{array}{c}\text { EC50 } \\
\text { after ischemia } \\
(-\log \text { mol/L) }\end{array}$ & $\begin{array}{c}\text { Vdil max } \\
\text { before ischemia } \\
(\%)\end{array}$ & $\begin{array}{c}\text { Vdil } \\
\text { after ischemia } \\
(\%)\end{array}$ \\
\hline Single infusion & $5.6 \pm 0.1$ & $5.0 \pm 0.1^{*}$ & $98 \pm 1$ & $82 \pm 4^{*}$ \\
Multiple infusions & $5.6 \pm 0.2$ & $5.3 \pm 0.0^{* \dagger}$ & $99 \pm 2$ & $89 \pm 5$ \\
\hline
\end{tabular}

${ }^{*} p<0.05$ compared with preischemic value.

$t_{p}<0.05$ compared with single-infusion postischemic value.

Ischemic periods of $60,90,120,150$, and 180 minutes were studied. The study was randomized both with respect to the duration of ischemia and the use of the cardioplegic solution.

ISCHEMIA-ALONE STUDY GROUP. After endothelial and smooth muscle function were assessed, the mesentery was perfused with drug-free perfusion fluid for 18 minutes before being rendered ischemic.

ISCHEMIA-PLUS-CARDIOPLEGIC-SOLUTION STUDY GROUP. After endothelial and smooth muscle function were assessed, the mesentery was perfused for 15 minutes with drug-free perfusion fluid. The mesentery was then perfused with St. Thomas' Hospital cardioplegic solution No. $2\left(37^{\circ} \mathrm{C}, 60 \mathrm{~cm} \mathrm{H}{ }_{2} \mathrm{O}\right)$ for 3 minutes before the tissue was rendered ischemic. In this way the cardioplegic solution was trapped in the vascular space for the duration of the ischemic period.

Single infusion versus multiple infusions of cardioplegic solution. These experiments were done with an ischemic duration of 150 minutes. For the single-infusion group the protocol was as already described. For the multiple-infusion group, the cardioplegic solution was infused for 3 minutes before ischemia and also every 30 minutes throughout the 150 minutes of ischemia (a total of five infusions).

Perfusion solution. The perfusion solution contained (in millimoles per liter) glucose $11.1, \mathrm{NaCl} 118.5, \mathrm{KCl} 4.75$, $\mathrm{MgSO}_{4} 1.19, \mathrm{KH}_{2} \mathrm{PO}_{4} 1.18, \mathrm{NaHCO}_{3} 25.0$, and $\mathrm{CaCl}_{2}$ I.36. It was gassed with $95 \%$ oxygen plus $5 \%$ carbon dioxide $(\mathrm{pH} 7.4$ at $37^{\circ} \mathrm{C}$ ). Before use, the solution was passed through a membrane filter of $5 \mu \mathrm{m}$ porosity.

Cardioplegic solution. The composition of the St. Thomas' Hospital cardioplegic solution No. 2 is (in millimoles per liter) $\mathrm{NaCl} 110.0, \mathrm{KCl} 16.0, \mathrm{MgCl}_{2}$ 16.0, $\mathrm{CaCl}_{2}$ 1.2, and $\mathrm{NaHCO}_{3}$ 10.0. The solution was titrated to $\mathrm{pH} 7.8$ and passed through a $5 \mu \mathrm{m}$ membrane filter before use.

Drugs. The drugs 1-phenylephrine hydrochloride, adenosine $5^{\prime}$-triphosphate disodium salt, and sodium nitroprusside were obtained from Sigma Chemical Company Ltd., St. Louis, Missouri. All drugs were dissolved in the perfusion solution to achieve the final concentrations stated. Because the fluid in tubing 2 was diluted approximately tenfold by the flow in tubing 1 , the drug concentration in the mesenteric bed was approximately one tenth that of the stock solutions. The concentration of phenylephrine used was chosen on the basis of previous dose-response studies that demonstrated that this dose produced maximal vasoconstriction. Previous studies also demonstrated that the ATP-induced vasodilation was endothelium-mediated inasmuch as it was completely abolished by 2 minutes of perfusion with saponin $(0.04 \mathrm{mg} / \mathrm{ml})$, whereas the vasodilator response to sodium nitroprusside was unaltered. All drugs were prepared fresh daily and sodium nitroprusside solutions were protected from light.

Data analysis. The vasoconstrictor response to phenylephrine was calculated by subtracting the baseline pressure from the stable pressure in response to phenylephrine. Because this value varied slightly before and after the ATP dose-response study, the value taken was the higher of the two values. This was regarded as the maximal vasoconstrictor response to phenylephrine. The postischemic response was calculated in the same way. Because there was a wide variation between mesenteries in the preischemic vasoconstrictor response to phenylephrine (range 82 to $199 \mathrm{~mm} \mathrm{Hg}$ ), the postischemic vasoconstrictor response was expressed as a percent of the individual preischemic response. The vasodilator responses to ATP and nitroprusside were expressed as a percent of the phenylephrineinduced vasoconstriction present immediately before performance of the dose-response study for each drug. For ATP and sodium nitroprusside, dose-response curves for each mesentery were fitted with a sigmoidal function with the use of an iterative curve-fitting program (GraphPad, ISI Software, Pleasanton, Calif.) and an IBM computer (IBM Corp., Armonk, N.Y.). From these curves the maximal vasodilator response ( $\mathrm{Vdil}$ max $)$ and the negative logarithm of the effective molar concentration that produced $50 \%$ of the maximal vasodilator response (EC50) were calculated.

In all experiments six mesenteries were studied in each group and the results are expressed as the mean plus or minus the standard error of the mean. Statistical evaluation of data for either paired or unpaired observations were done by Student's $t$ test. Differences were considered to be statistically significant when $p$ was less than 0.05 .

\section{Results}

Relation between duration of ischemia and postischemic vascular function with ischemia alone versus ischemia plus cardioplegic solution

Postischemic vasoconstriction to phenylephrine. There was a progressive decline dependent on the duration of ischemia in the vasoconstrictor response to phenylephrine in both study groups (Fig. 2). After 60 minutes of ischemia alone the contractile response was essentially unchanged from its preischemic control value $(99 \% \pm 13 \%$; the value for the ischemia-plus-cardioplegic-solution group was $89 \% \pm 5 \%$ ). The response fell 
Table IV. EC50 and Vdil $l_{\max }$ for sodium nitroprusside before and after 150 minutes of ischemia in mesenteries receiving either single or multiple infusions of cardioplegic solution

\begin{tabular}{lcccc}
\hline $\begin{array}{c}\text { Experimental } \\
\text { condition }\end{array}$ & $\begin{array}{c}\text { EC50 } \\
\text { before } \text { ischemia } \\
(-\log \text { mol/L) }\end{array}$ & $\begin{array}{c}\text { EC50 } \\
\text { after ischemia } \\
(-\log \text { mol/L) }\end{array}$ & $\begin{array}{c}\text { Vdil } l_{\text {max }} \\
\text { before ischemia } \\
(\%)\end{array}$ & $\begin{array}{c}\text { Vdil } \text { max } \\
\text { after ischemia } \\
(\%)\end{array}$ \\
\hline Single infusion & $5.0 \pm 0.1$ & $4.7 \pm 0.2$ & $92 \pm 3$ & $53 \pm 5^{*}$ \\
Multiple infusions & $5.0 \pm 0.2$ & $4.6 \pm 0.2^{*}$ & $94 \pm 2$ & $81 \pm 6 \dagger$ \\
\hline
\end{tabular}

${ }^{*} p<0.05$ compared with preischemic value.

$t_{p}<0.05$ compared with single-infusion postischemic value.

progressively as the duration of ischemia was increased so that after 180 minutes of ischemia alone it was only $27 \% \pm 4 \%$. In the ischemia-plus-cardioplegic-solution group the response also declined as the duration of ischemia increased; the value was only $18 \% \pm 3 \%$ after 180 minutes of ischemia. For all time intervals the mean postischemic vasoconstrictor response to phenylephrine tended to be less for the ischemia-plus-cardioplegic-solution group than that for the ischemia-alone group (Fig. 2); however, for no time interval was this difference statistically significant.

Postischemic smooth muscle vasodilation to sodium nitroprusside. The response to nitroprusside was unaffected by 60 minutes of ischemia alone, but in all other groups the $\mathrm{Vdil}_{\max }$ was significantly reduced compared with preischemic values (Table I and Figs. 3 and 4). This impairment increased with increasing durations of ischemia for both groups. Thus for the ischemia-alone group the mean value fell to $38 \% \pm 9 \%$ after 180 minutes of ischemia (Fig. 3) whereas the corresponding value was $44 \% \pm 7 \%$ when ischemia was combined with the cardioplegic solution (Fig. 4). The concentration of sodium nitroprusside required to achieve EC50 was only significantly changed in two groups (90 minutes of ischemia alone and 180 minutes of ischemia alone). There were no significant differences between the groups when they were matched for ischemic times.

Postischemic endothelium-dependent vasodilation to $A T P$. The Vdil $\mathrm{Imax}_{\text {mas }}$ wot significantly reduced for ischemic periods of up to 150 minutes; for both groups the values ranged from $87 \% \pm 7 \%$ to $96 \% \pm 2 \%$ (Table II and Figs. 5 and 6). After 180 minutes of ischemia, Vdil-

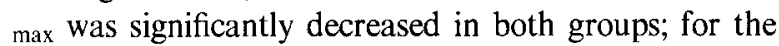
ischemia-alone group the value fell to $62 \% \pm 11 \%$ (Fig. 5) and for the ischemia-plus-cardioplegic-solution group it fell to $40 \% \pm 9 \%$ (Fig. 6). The concentration of ATP required to achieve $50 \%$ inhibition of the maximal phenylephrine-induced vasoconstriction was increased after 90 minutes for the ischemia-alone group and with longer durations of ischemia it was increased for both groups (Table II). This increase progressed as the dura- tion of ischemia increased so that after 90 minutes of ischemia alone the EC50 was $-\log 5.4 \pm 0.1 \mathrm{~mol} / \mathrm{L}$ whereas after 180 minutes it was $-\log 5.0 \pm 0.1 \mathrm{~mol} / \mathrm{L}$. For the ischemia-plus-cardioplegic-solution group the values were $-\log 5.3 \pm 0.1 \mathrm{~mol} / \mathrm{L}$ and $-\log 4.9 \pm 0.1$ $\mathrm{mol} / \mathrm{L}$, after 90 and 180 minutes of ischemia respectively.

Comparison of the effects of single infusion versus multiple infusions of cardioplegic solution on postischemic (150 minutes) vascular function

Postischemic vasoconstriction to phenylephrine. The maximal vasoconstrictor response to phenylephrine in the single-infusion cardioplegic group was $21 \% \pm 4 \%$ of the preischemic response (Fig. 7). This was significantly lower $(p<0.05)$ than that achieved in the multiple-infusion group $(74 \% \pm 4 \%)$ (Fig. 7$)$.

Postischemic vasodilation to sodium nitroprusside. Preischemic values for EC50 and Vdil max $_{\text {ax }}$ were similar for both groups (Table III). After ischemia the Vdil ${ }_{\max }$ was significantly reduced $(p<0.05)$ in the single-infusion group $(53 \% \pm 5 \%)$ compared with both its preischemic value $(92 \% \pm 3 \%)$ and the postischemic value for the multiple-infusion group $(81 \% \pm 6 \%)$ (Fig. 8$)$. The Vdilmax to nitroprusside was not significantly affected in the multiple-infusion group (Table III).

Postischemic endothelium-dependent vasodilation to $A T P$. The EC50 and Vdil max $_{\text {max }}$ were similar in both groups before ischemia (Table IV). For both groups the EC50 was significantly higher $(p<0.05)$ after ischemia and was also significantly higher for the single-infusion group $(-\log 5.0 \pm 0.1 \mathrm{~mol} / \mathrm{L})$ in comparison with that for the multiple-infusion group $(-\log 5.3 \pm 0.0 \mathrm{~mol} / \mathrm{L})$. The Vdil $_{\max }$ was significantly reduced $(p<0.05)$ compared with its preischemia value in the single-infusion group $(82 \% \pm 4 \%$ versus $98 \% \pm 1 \%)$, but not significantly reduced in the multiple-infusion group ( $89 \% \pm 5 \%$ versus $99 \% \pm 2 \%$; Table IV and Fig. 9).

\section{Discussion}

Justification of the mesentery as a model. We have established a vascular bed preparation that allows us to 


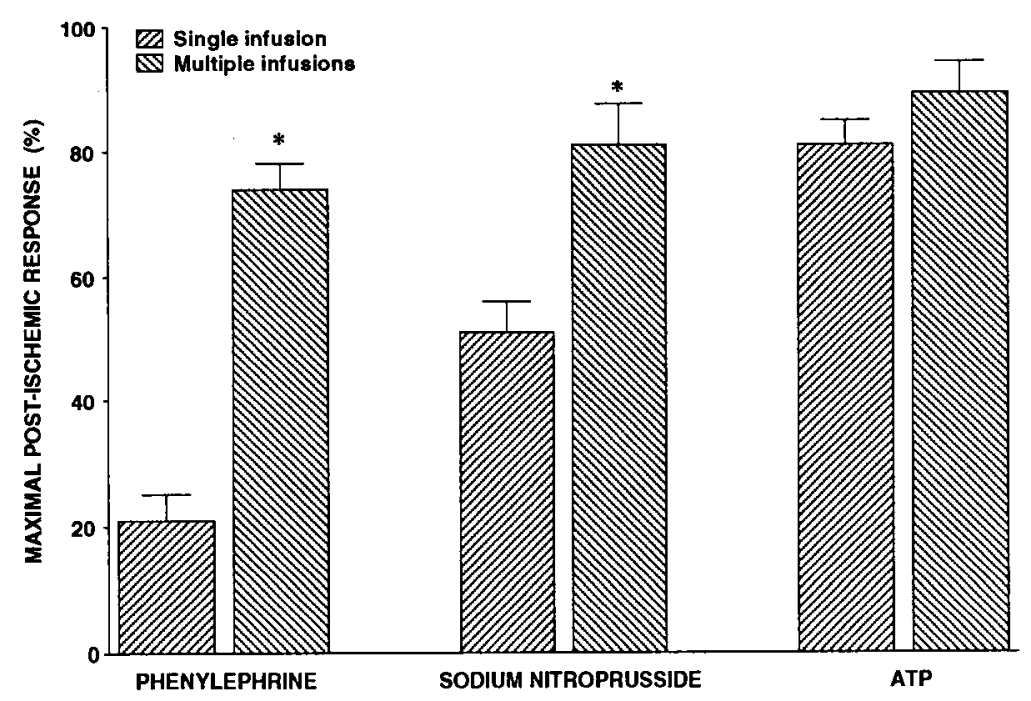

Fig. 7. Maximal postischemic responses to phenylephrine, sodium nitroprusside, and ATP after 150 minutes of ischemia with single or multiple infusions of cardioplegic solution. Phenylephrine vasoconstrictor response is expressed as percent of preischemic response. Sodium nitroprusside and ATP vasodilator responses are expressed as percent of postischemic phenylephrine-induced vasoconstriction.

differentiate the effects on vascular function of ischemia from those of the St. Thomas' Hospital No. 2 cardioplegic solution. The model was established so that vascular function could be assessed independently of all extravascular factors that might otherwise affect the interpretation of vascular function in whole hearts. This complication may be overcome by the use of isolated conduit vessels, but the perfused mesentery is a more physiologic preparation for the study of vascular function. It could be argued that, because there is heterogeneity between vascular beds, ${ }^{29,} 30$ the results are not applicable to the coronary vascular bed. However, it is our belief that there are more similarities than differences between beds, a position that is supported by the fact that studies on ischemia and reperfusion that used mesenteric beds ${ }^{31}$ have produced similar findings to those of studies that used hearts. ${ }^{12,13}$ Moreover, models other than the heart have been used to study the effects of cardioplegic solutions, ${ }^{15,26,32,33}$ and useful knowledge has been gained from them.

Effects on vascular function of ischemia with and without cardioplegic solution. With the use of the mesenteric bed preparation, we have compared the effects on vascular function of ischemia alone versus those of ischemia with cardioplegic solution present in the vascular space for the entire duration of ischemia during ischemic periods ranging from 60 to 180 minutes. We found that normothermic ischemia alone caused a progressive time-dependent deterioration of both smooth muscle and endothelial-mediated responses. A similar trend was observed in mesenteries subjected to ischemia with the cardioplegic solution. When matched for ischemic times there were no significant differences between the two groups with respect to responses to phenylephrine or the maximal relaxation response to sodium nitroprusside or ATP. The results therefore suggest that whereas the St. Thomas' Hospital cardioplegic solution did not compound the ischemia-induced injury, it likewise failed to confer any protection to the vasculature against injury induced by ischemia and reperfusion.

Effects on vascular function of single and multiple infusions of cardioplegic solution. In an attempt to determine whether the cardioplegic solution caused any damage per se to the endothelium or failed to protect against ischemic injury, multiple infusions of cardioplegic solutions were studied. The rationale for this was that if the solution did cause any damage then this would be exacerbated by multiple infusions; conversely, if the solution simply failed to afford protection, then (by analogy with ischemic myocytes) multiple infusions might have a protective effect. ${ }^{23} \mathrm{We}$ found that with 150 minutes of ischemia, multiple infusions did result in superior protection to both smooth muscle and endothelial function when compared with a preischemic single infusion. The results therefore indicate that damage to the vasculature is predominantly a result of failure of the solution to protect against ischemic injury rather than a toxic effect of the solution.

Other studies that support the findings of the present study. The conclusion that vascular damage during cardioplegia is predominantly a result of the ischemic com- 


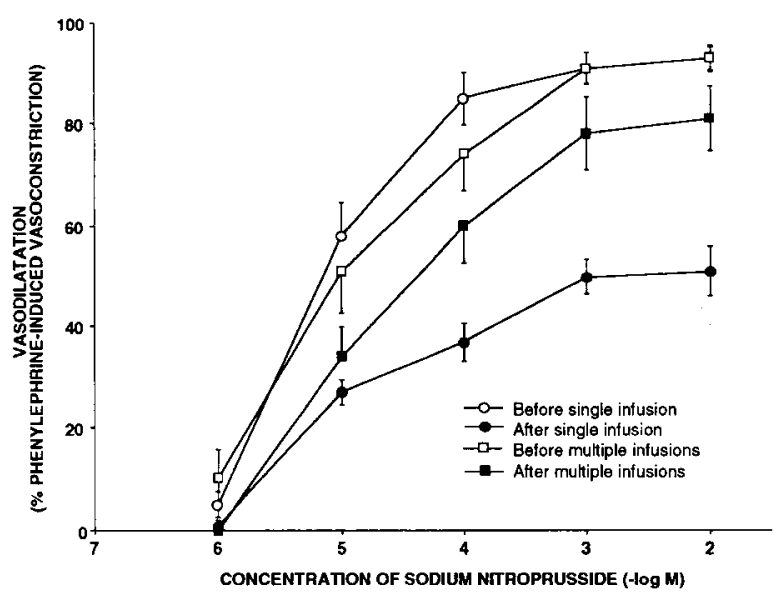

Fig. 8. Vasodilation to sodium nitroprusside expressed as percent of phenylephrine-induced vasoconstriction before and after 150 minutes of ischemia with single or multiple infusions of cardioplegic solution.

ponent rather than a toxic effect of the solution is supported by several other studies that have demonstrated that agents that have a protective effect on the vasculature against ischemia-reperfusion injury ${ }^{34-36}$ also have a protective effect when added to the cardioplegic solution. ${ }^{32,37,38}$ Two other studies have compared the effects of single and multiple infusions of cardioplegic solutions on vascular function. In one, the isolated crystalloid-perfused rat heart was used to compare the effects of single and multiple infusions of the St. Thomas' Hospital No. 1 solution against those of 90 minutes of ischemia. ${ }^{39}$ In the other study (unpublished observations) we used the isolated blood-perfused piglet heart to compare the effects of these two modes of administration with both the St. Thomas' Hospital No. 1 and No. 2 cardioplegic solutions against 6 and 8 hours of ischemia. Both studies demonstrated superior protection of vascular function with multiple infusions compared with that of single infusions. It should be noted, however, that both these studies involved hypothermia and the effect of hypothermia on the endothelium is a topic of controversy. $26,27,40,41$

Time course of vascular damage. In the present study we demonstrated that smooth muscle function was impaired before endothelial function. This finding is at variance with those of many other studies that have demonstrated that ischemia plus reperfusion produces endothelial dysfunction before smooth muscle dysfunction. ${ }^{21}, 22,36,42-45$ The explanation for the discrepancy in results between this study and previous studies may be related to differences in the agents and models used for the assessment of endothelial function. The decision to use ATP in the present study was made for two reasons. First,

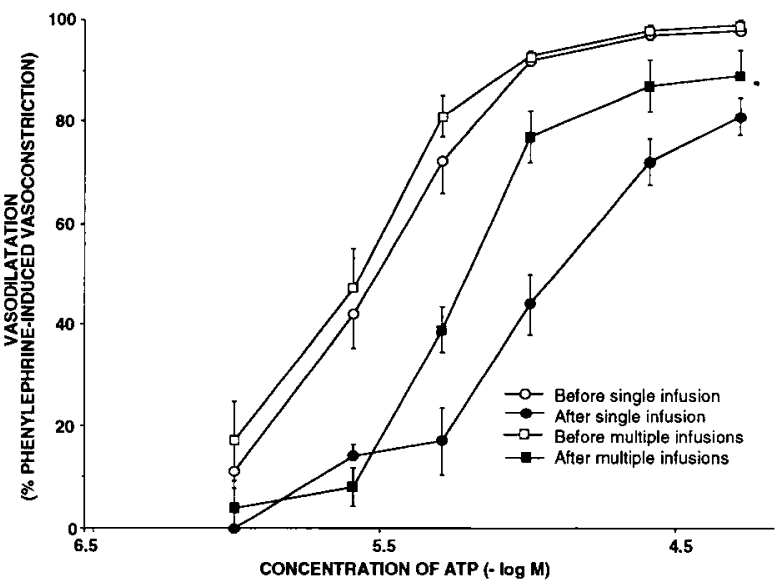

Fig. 9. Vasodilation to ATP expressed as percent of phenylephrine-induced vasoconstriction before and after 150 minutes of ischemia with single or multiple infusions of cardioplegic solution.

it is an agent that is relevant from a physiologic and pathophysiologic view. Increased ATP concentrations have been demonstrated in the coronary effluent after hypoxia, ${ }^{46}$ and ATP is released from aggregating platelets ${ }^{47}$ and causes vasoconstriction rather than vasodilation in vessels when the endothelium is damaged. ${ }^{48}$ Second, although ATP is an endothelium-dependent relaxant (confirmed by the use of saponin in preliminary experiments), its vasodilatory action may be mediated by a number of different mechanisms including the release of EDRF ${ }^{49}$ the release of prostanoids, ${ }^{50}$ and degradation to adenosine. $^{51}$ To our knowledge the exact contribution of each of these mechanisms to endothelium-dependent vasodilation in the rat mesenteric bed has not been characterized. In the guinea pig heart it has been suggested that prostanoids play a major role whereas EDRF plays a minor role in mediating the endothelium-dependent relaxation by ATP. ${ }^{52}$ This is important because previous experiments that demonstrated early endothelial dysfunction after ischemia and reperfusion have mainly used agonists whose vasodilatory action is achieved predominantly through the release of EDRF. ${ }^{21,22,36,42-45}$ However, EDRF is rapidly broken down by free radicals, ${ }^{53,54}$ and it has been recently demonstrated that impaired endothelium-mediated relaxation in diabetic rat aortas is not caused by failure of production of EDRF but is caused by increased destruction of EDRF by free radicals. ${ }^{55,56}$ Because free radicals are known to be generated after ischemia and reperfusion, ${ }^{12,57-60}$ a possible explanation for the significant reduction in the maximal response to sodium nitroprusside after only 90 minutes of ischemia is that the nitric oxide released by the sodium nitroprusside 
was destroyed by free radicals before it reached the smooth muscle cells. The loss in efficacy to sodium nitroprusside was not a result of smooth muscle damage because maximal smooth muscle relaxation could still be achieved in response to ATP. The response to ATP could have been maintained because the mechanisms of its vasodilatory action are not confined to the release of EDRF, which would also be destroyed by free radicals.

Another explanation for the discrepancy between results of the present study and previous studies may be related to differences in models. Most previous studies that demonstrated impaired endothelial function before smooth muscle dysfunction used isolated vessel preparations. ${ }^{21,22,42-45}$ However, in these preparations the nitric oxide released from endothelium-independent vasodilators can reach the smooth muscle cells from the adventitial surface. Therefore any loss in sensitivity or efficacy of nitric oxide caused by the destruction by free radicals generated within the endothelial cells may not be revealed. In the isolated mesenteric preparation, drugs or their active metabolites have to cross the endothelium to reach the smooth muscle.

Cautions in extrapolating the results to other solutions and other endothelial functions. Because there are wide differences in the composition and cytotoxicity of cardioplegic solutions, ${ }^{15}$ the findings of this study cannot necessarily be extrapolated to other cardioplegic solutions. On the evidence of previous studies, it is likely that multiple infusions of cardioplegic solutions with potassium concentrations of $25 \mathrm{~mol} / \mathrm{L}$ or higher are likely to be more detrimental to the endothelium than a single infusion, ${ }^{19,20}$ particularly if high infusion pressures are used. ${ }^{61}$ It should also be noted that endothelium-mediated vasodilation is only one endothelial function and it cannot be assumed that it is representative of all other endothelial functions. Indeed some other functions such as permeability might be made worse by multiple infusions of crystalloid cardioplegic solutions. ${ }^{62}$

Conclusions. The present study has demonstrated that normothermic ischemia alone results in progressive, timedependent damage to both smooth muscle and endothelial function. This damage is not significantly different from that seen in tissues rendered ischemic with coincident exposure to the St. Thomas' Hospital No. 2 cardioplegic solution, which suggests that this cardioplegic solution fails to protect the vasculature against ischemiareperfusion injury and does not inflict any additional injury to the vasculature. Further evidence to support this hypothesis was provided by our observation that, in comparison with single infusions, multiple infusions of cardioplegic solution had a protective effect on both smooth muscle and endothelial function after 150 minutes of ischemia. More experiments are undoubtedly required to identify the optimal solution and conditions for protecting both the myocytes and the vasculature against injury during ischemia and reperfusion. However, the results of this study suggest that, with respect to the St. Thomas' Hospital No. 2 cardioplegic solution, future research may be more profitably directed to determining how it may be improved to protect the vasculature against ischemiareperfusion injury rather than trying to identify potentially damaging factors in it.

The advice and discussion of Drs. M. J. Shattock, W. A. Coetzee, C. S. Lawson, and M. Avkiran are gratefully acknowledged.

\section{REFERENCES}

1. Hearse DJ, Braimbridge MV, Jynge P. Protection of the ischemic myocardium: cardioplegia. New York: Raven Press, 1981.

2. Finney RS, Gardner TJ. Myocardial protection after 15 years of cardioplegia. Curr Opin Cardiol 1990;5:226-34.

3. Hearse DJ, Maxwell L, Saldanha C, Gavin JB. The myocardial vasculature during ischemia and reperfusion: a target for injury and protection. J Mol Cell Cardiol 1993; 25:759-800.

4. Forman MB, Puett DW, Virmani R. Endothelial and myocardial injury during ischemia and reperfusion: pathogenesis and therapeutic implications. J Am Coll Cardiol 1989;13:450-9.

5. Anversa P, Levicky V, Beghi C, McDonald SL, Kikkawa Y. Morphometry of exercise-induced right ventricular hypertrophy in the rat. Circ Res 1983;52:57-64.

6. Petty RG, Pearson JD. Endothelium: the axis of vascular health and disease. J R Coll Physicians Lond 1989;23:92102.

7. Luscher TF, Richard V, Tschudi M, Yang Z, Boulanger C. Endothelial control of vascular tone in large and small coronary arteries. J Am Coll Cardiol 1990;15:519-27.

8. Henderson AH. Endothelium in control. Br Heart J 1991; 65:116-25.

9. Gerlach E, Nees S, Becker BF. The vascular endothelium: a survey of some newly evolving biochemical and physiological features. Basic Res Cardiol 1985;80:459-74.

10. Furchgott RF, Zawadzki JV. The obligatory role of endothelial cells in the relaxation of arterial smooth muscle by acetylcholine. Nature 1980;288:373-6.

11. Palmer RMJ, Ferrige AG, Moncada S. Nitric oxide release accounts for the biological activity of endothelium-derived relaxant factor. Nature 1987;327:524-6.

12. Lefer AM, Lefer DJ. Endothelial dysfunction in myocardial ischemia and reperfusion: role of oxygen-derived free radicals. Basic Res Cardiol 1991;2:109-16.

13. Lefer AM, Tsao PS, Lefer DJ, Ma XL. Role of endothelial dysfunction in the pathogenesis of reperfusion injury after myocardial ischemia. FASEB J 1991;5:2029-34.

14. Pearson PJ, Schaff HV, Vanhoutte PM. Long-term impair- 
ment of endothelium-dependent relaxations to aggregating platelets after reperfusion injury in canine coronary arteries. Circulation 1990;81:1921-7.

15. Carpentier S, Murawsky M, Carpentier A. Cytotoxicity of cardioplegic solutions: evaluation by tissue culture. Circulation 1981;64(Suppl):II90-5.

16. Follette DM, Buckberg GD, Mulder GD, et al. Deleterious effects of crystalloid cardioplegic solutions on arterial endothelial cells. Surg Forum 1980;31:25-8.

17. Harjula A, Mattila S, Mattila I, et al. Coronary endothelial damage after crystalloid cardioplegia. J Cardiovasc Surg (Torino) 1984;25:147-52.

18. Harjula AL, Mattila S, Jarvinen A, Myllarniemi $H$, Salmenpera M. Endothelial cell damage following crystalloid cardioplegic solution infusion: scanning electron microscope study of coronary bypass grafts. Arch Surg 1984; 119:946-9.

19. Mankad PS, Chester AH, Yacoub MH. Role of potassium concentration in cardioplegic solutions in mediating endothelial damage. Ann Thorac Surg 1991;51:89-93.

20. Saldanha C, Hearse DJ. Coronary vascular responsiveness to 5-hydroxytryptamine before and after infusion of hyperkalemic crystalloid cardioplegic solution in the rat heart: possible evidence of endothelial damage. J THORAC CARDIOVASC SURG 1989;98:783-7.

21. Ku DD. Coronary vascular reactivity after acute myocardial ischemia. Science 1982;218:576-8.

22. VanBenthuysen KM, McMurtry IF, Horwitz LD. Reperfusion after acute coronary occlusion in dogs impairs endothelium-dependent relaxation to acetylcholine and augments contractile reactivity in vitro. J Clin Invest 1987;79:265-74.

23. Engelman RM, Auvil J, O’Donoghue MJ, Levitsky S. The significance of multidose cardioplegia and hypothermia in myocardial preservation during ischemic arrest. J THORAC Cardiovasc Surg 1978;76:555-63.

24. Kempsford RD, Hearse DJ. Protection of the immature heart: temperature-dependent beneficial or detrimental effects of multidose crystalloid cardioplegia in the neonate rabbit heart. J THORAC CARDIOVASC SURG 1990;99:26979.

25. Magovern JA, Pae WE, Miller CA, Waldhausen JA. The immature and mature myocardium: responses to multidose crystalloid cardioplegia. J THORAC CARDIOVASC SURG 1988;95:618-24.

26. Solberg S, Larsen T, Jorgensen L, Sorlie D. Cold-induced endothelial detachment in human saphenous vein grafts. $J$ Cardiovasc Surg (Torino) 1987;2830:571-5.

27. Aoki M, Kawata H, Mayer JE. Coronary endothelial injury by cold crystalloid cardioplegic solution in neonatal lambs. Circulation 1992;86(Suppl):II346-51.

28. McGregor DD. The effect of sympathetic nerve stimulation on vasoconstrictor responses in perfused mesenteric blood vessels of the rat. J Physiol 1965;177:21-63.

29. Furchgott RF. Role of endothelium in responses of vascular smooth muscle. Circ Res 1983;53:557-73.

30. Vanhoutte PM, Rimele TJ. Role of the endothelium in the control of vascular smooth muscle function. J Physiol (Paris) $1983 ; 78: 681-6$.

31. Lefer AM, Ma XL. Endothelial dysfunction in the splanchnic circulation following ischemia and reperfusion. J Cardiovasc Pharmacol 1991;17(suppl 3):186-90.

32. Keller MW, Geddes L, Spotnitz W, Kaul S, Duling BR. Microcirculatory dysfunction following perfusion with hyperkalemic, hypothermic, cardioplegic solutions and blood reperfusion: effects of adenosine. Circulation 1991; 84:2485-94.

33. Singh AK, Capone RJ, O'Shea P, Karlson KE. Long-term changes in canine vein grafts after infusion of cardioplegic solution. Circulation 1983;68:112-6.

34. Forman MB, Puett DW, Bingham SE, et al. Preservation of endothelial cell structure and function by intracoronary perfluorochemical in canine preparation of reperfusion. Circulation 1987;76:469-79.

35. Olafsson B, Forman MB, Puett DW, et al. Reduction of reperfusion injury in the canine preparation by intracoronary adenosine: importance of the endothelium and the no-reflow phenomenon. Circulation 1987;76:1135-45.

36. Tsao PS, Lefer AM. Time course and mechanism of endothelial dysfunction in isolated ischemic- and hypoxicperfused rat hearts. Am J Physiol 1990;28:H1660-6.

37. Harjula A, Mattila S, Myllarniemi H, et al. Effects of synthetic blood and crystalloid cardioplegic solutions on coronary endothelium: an experimental scanning electron microscope study. J Surg Res 1985;39:405-12.

38. Sellke FW, Shafique T, Schoen FJ. Impaired endotheliumdependent coronary microvascular relaxation after cold potassium cardioplegia and reperfusion. $\mathbf{J}$ THORAC CARDIOVASC SURG 1993;105:52-8.

39. Mankad PS, Chester AH, Yacoub MH. Ischaemic endothelial dysfunction after single or multidose cardioplegia. Eur Heart J 1992;13:976-80.

40. Amrani M, Mankad PS, Yacoub MH. Improved preservation of endothelial function at 4 degrees $C$. Eur $\mathbf{J}$ Cardiothorac Surg 1992;6:72-8.

41. Fremes SE, Li RK, Weisel RD, Mickle DA, Tumiati LC. Prolonged hypothermic cardiac storage with University of Wisconsin solution: an assessment with human cell cultures. J Thorac Cardiovasc Surg 1991;102:666-72.

42. Quillen JE, Sellke FW, Brooks LA, Harrison DG. Ischemia-reperfusion impairs endothelium-dependent relaxation of coronary microvessels but does not affect large arteries. Circulation 1990;82:586-94.

43. Pearson PJ, Schaff HV, Vanhoutte PM. Acute impairment of endothelium-dependent relaxations to aggregating platelets following reperfusion injury in canine coronary arteries. Circ Res 1990;67:385-93.

44. Pearson PJ, Lin PJ, Schaff HV. Global myocardial ischemia and reperfusion impair endothelium-dependent relaxations to aggregating platelets in the canine coronary artery: a possible cause of vasospasm after cardiopulmonary bypass. J THORAC CARdiovasC SURG 1992;103: 1147-54.

45. Tsao PS, Aoki N, Lefer DJ, Johnson G, Lefer AM. Time 
course of endothelial dysfunction and myocardial injury during myocardial ischemia and reperfusion in the cat. Circulation 1990;82:1402-12.

46. Clemens MG, Forrester T. Appearance of adenosine triphosphate in the coronary sinus effluent from isolated working rat heart in response to hypoxia. J Physiol (Lond) 1981;312:143-58.

47. Ingerman CM, Smith JB, Silver MJ. Direct measurement of platelet secretion in whole blood. Thromb Res 1979; 16:335-44.

48. Vanhoutte PM. Could the absence or malfunction of vascular endothelium precipitate the occurrence of vasospasm? J Mol Cell Cardiol 1986;18:679-86.

49. Kelm M, Schrader J. Control of coronary vascular tone by nitric oxide. Circ Res 1990;66:1561-75.

50. Needleman P, Minkes MS, Douglas JR. Stimulation of prostaglandin biosynthesis by adenine nucleotides. Circ Res 1974;34:455-60.

51. Moody CJ, Meghji P, Burnstock G. Stimulation of P1purinoceptors by ATP depends partly on its conversion to AMP and adenosine and partly on direct action. Eur $\mathrm{J}$ Pharmacol 1984;97:47-54.

52. Brown IP, Thompson CI, Belloni FL. Mechanisms of coronary vasodilatation produced by ATP in guinea-pig isolated heart. Br J Pharmacol 1992;105:211-5.

53. Rubanyi GM, Vanhoutte PM. Superoxide anions and hyperoxia are involved in the breakdown of endothelium-derived relaxing factor. Am J Physiol 1986;250: H822-7.
54. Gryglewski RJ, Palmer RMJ, Moncada S. Superoxide anion is involved in the breakdown of endothelium-derived vascular relaxing factor. Nature 1986;320:454-6.

55. Langenstroer $P$, Pieper GM. Regulation of spontaneous EDRF release in diabetic rat aorta by oxygen free radicals. Am J Physiol 1992;263:H257-65.

56. Pieper GM, Mei DA, Langenstroer P, O’Rourke ST. Bioassay of endothelium-derived relaxing factor in diabetic rat aorta. Am J Physiol 1992;263:H676-80.

57. Ferrari R, Ceconi C, Cureelo S, Cargnoni A, Medici D. Oxygen free radicals and reperfusion injury: the effect of ischemia and reperfusion on the cellular ability to neutralise oxygen toxicity. J Mol Cell Cardiol 1986;18:67-9.

58. Garlick PB, Davies MJ, Hearse DJ, Slater TF. Direct detection of free radicals in the reperfused rat heart using electron spin resonance spectroscopy. Circ Res 1987; 61:757-60.

59. Flaherty JT, Weisfeldt ML. Reperfusion injury. Free Radic Biol Med 1988;3:409-14.

60. Kukreja RC, Hess ML. The oxygen free radical system: from equations through membrane-protein interactions to cardiovascular injury and protection. Cardiovasc Res 1992;26:641-55.

61. Cartier R, Pellerin M, Hollmann C, Pelletier LC. Effects of pressure and duration of hyperkalemic infusions on endothelial function. Ann Thorac Surg 1993;55:700-5.

62. Mann GE. Alterations of myocardial capillary permeability in isolated, perfused rabbit hearts. J Physiol 1981; 319:311-23.

\section{Availability of Journal back issues}

As a service to our subscribers, copies of back issues of THE JOURNAL of THORACIC AND CARDIOvascular SURGERY for the preceding 5 years are maintained and are available for purchase from the publisher, Mosby-Year Book, Inc., at a cost of $\$ 10.50$ per issue. The following quantity discounts are available: $25 \%$ off on quantities of 12 to 23 , and one third off on quantities of 24 or more. Please write to Mosby-Year Book, Inc., Subscription Services, 11830 Westline Industrial Drive, St. Louis MO $63146-$ 3318 , or call (800)453-4351 or (314)453-4351 for information on availability of particular issues. If unavailable from the publisher, photocopies of complete issues are available from University Microforms International, $300 \mathrm{~N}$. Zeeb Rd., Ann Arbor, MI 48106, (313) 761-4700. 